\title{
A metodologia hermenêutica como elemento determinante na interpreta- ção do relato bíblico da criação
}

\author{
MARLON ROBERTO VARELA TEXEIRA ${ }^{1}$ \\ CARLOS FLÁVIO TEIXEIRA
}

\begin{abstract}
Resumo: Há séculos os estudiosos da Bíblia debatem a interpretação do relato de Gênesis 1:12:3 acerca da criação do mundo. Essa discussão, que no passado era motivada por tentativas exegéticas e filosóficas de resolver pontos controvertidos de compreensão, foi intensificada com as hipóteses geológicas e biológicas que surgiram no meio científico, notadamente a partir dos séculos 18 e 19. Tais perspectivas apresentam versões diferentes sobre as origens, em relação à visão mais antiga que entende os sete dias em que a vida foi criada como tendo, cada um, duração de 24 horas e sendo, portanto, literais e históricos. Mais do que uma mera questão de diferenças de opinião, uma observação atenta desse panorama aponta que a principal causa das divergências interpretativas pode ser notada nas opções metodológicas feitas pelos intérpretes das Escrituras, fato que se mostra elementar para a observação e discussão não apenas desse, mas também de outros temas teológicos.
\end{abstract}

Palavras-Chave: Bíblia; Gênesis; relato da criação; metodologias de interpretação; perspectivas.

\section{The hermeneutic methodology as a determin- ing element in the interpretation of the Bibli- cal account of the creation}

\footnotetext{
1 Graduado em Teologia pelo Centro Universitário Adventista de São Paulo. E-mail: marlontexeira@gmail.com.

2 Doutorando em Teologia Bíblico-Sistemática na Andrews University (EUA), Doutor em Teologia Bíblico-Sistemática pela Escola Superior de Teologia (EST). Doutor em Ciências da Religião, na especialidade de Teologia Sistemática pela Universidade Metodista de São Paulo (UMESP). Mestre em Teologia Pastoral (UNASP) e Direito Constitucional (UNIMEP). Especialista em Docência Para o Ensino Superior (UNISUL). Membro da SBL (Society of Biblical Literature), ATS (Adventist Theological Society), ABIB (Associação Brasileira de Pesquisa Bíblica) e SOTER (Sociedade de Teologia e Ciências da Religião). Docente e pesquisador no SALT - Seminário Adventista Latino-Americano de Teologia. Avaliador do MEC/INEP para cursos de graduação. E-mail: carlosflavioteixeira@gmail.com.
} 


\begin{abstract}
Bible scholars have debated the interpretation of Genesis 1:1-2:3 about the creation of the world for centuries. This discussion, that for a long time has been motivated by exegetical and philosophical attempts of solving controversial points of comprehension, was intensified with the geological and biological hypotheses that arose in the scientific midst, notably since centuries 18 and 19. Such perspectives present different versions about the origins, in relation to the oldest version that understands the seven days in which life was created as having, each one, 24 hours of duration and being, therefore, literal and historical. More than a mere point of difference of opinions, an attentive observation of this overview points out that the main reason of the interpretative divergences can be noticed in the methodological options made by the Scriptures interpreters, a fact that comes out as elementary for the observation and discussion not only of this one, but also of other theological themes.
\end{abstract}

Keywords: Bible; Genesis; story of creation; interpretation methodologies; perspective.

A multiplicidade de crenças e práticas presentes no cristianismo evidencia que existem inúmeras interpretações a respeito de pontos específicos da Bíblia. Uma das controvérsias mais antigas gira em torno da maneira correta de se entender os "dias" nos quais a Bíblia menciona ter ocorrido a criação do planeta Terra, de sua redondeza cósmica e dos seres vivos que nele habitam. Nas palavras de Moskala, estão evidentes as três principais perspectivas sobre o assunto: a alegórica, a evolutiva e a literal:

Os dias da criação têm sido entendidos de diferentes maneiras. Alguns interpretam-nos como dias simbólicos; outros como uma descrição poética ou um relato evolutivo da atividade criativa de Deus; ainda outros os veem como uma revelação de Deus e os tomam como dias literais. (MOSKALA, 2010, p. 116, tradução livre)

Na perspectiva de Kaiser Jr. (1980, p. 75), "muitas vezes, o debate quanto ao tempo levado pela criação consome mais tempo e energia do que o necessário. A teologia em geral não tem interesse nesse debate". Canale, por outro lado, afirma que

os cristãos precisam reafirmar o fato de que uma compreensão teológica de Gênesis 1, descrevendo o período de seis dias consecutivos de 24 horas literais e históricos durante os quais Deus criou a vida em nosso planeta, é essencial ao pensamento teológico das Escrituras e, portanto, ao sistema harmônico da verdade que originou o cristianismo e sua missão global. (CANALE, 2014, p. 116)

Tal debate pode ser resumido em uma pergunta: "os seis dias de 24 horas apresentados em Gênesis 1 são um componente essencial da verdade teológica”? (CANALE, 2014, p. 108). Com vistas a responder essa pergunta, o presente artigo relembra o panorama geral sobre a interpretação dos dias da criação (em Gênesis 1) ao longo do tempo. Depois disso, será destacada a perícope de Gênesis 1:1-2:3, de modo a notar no próprio texto as evidências ali reivindicadas para o significado da palavra "dia", corroborando-se a isso a perspectiva de diversos autores. Em seguida, serão consideradas as questões metodológicas envolvidas nesse debate. 


\section{Breve histórico da interpretação dos dias da criação}

A história da interpretação dos dias da criação mostra, como conclui Lewis (1989, p. 455), que "os leitores da Bíblia nunca tiveram uma única forma de pensar a respeito dos dias da criação". Desde Filo de Alexandria, intérprete judeu do primeiro século, até os dias atuais, sempre houve os que entenderam de forma não literal o relato criativo.

Segundo Shea (2011, p. 495-496), fontes judaicas intertestamentárias, bem como Flávio Josefo, seguiam bem de perto o relato criativo de Gn 1 e 2, com a diferença de detalhes acrescentados. O Livro dos Jubileus, por exemplo, afirma, sobre a criação:

E o anjo da presença falou a Moisés de acordo com a palavra do Senhor, dizendo: escreva a história completa da criação, como em seis dias o Senhor Deus terminou todas as suas obras e tudo o que criou, e guardou o sábado no sétimo dia e o santificou por todas as eras, e o designou como sinal para todas as suas obras (CHARLES, 1902, 2.1, tradução livre).

É interessante notar, entretanto, que na mesma obra já havia a possibilidade de definir "dia" em termos de períodos maiores, por razões alegadamente exegéticas:

E ele faltou setenta anos de mil anos; porque mil anos é como um dia no testemunho dos céus e por isso está escrito a respeito da árvore do conhecimento: "no dia que comeres dela morrerás". Por essa razão ele não completou os anos do seu dia; porque morreu durante ele (CHARLES, 1902, 4.30, tradução livre).

Ao que parece, como Gênesis 2:17 diz "porque, no dia (yôm) em que dela comeres, certamente morrerás", mas Adão viveu 930 anos (Gn 5:5), o autor sentiu a necessidade de explicar a aparente contradição. Para entender o "dia" do qual Gênesis 2:17 fala, o autor recorreu a uma chave hermenêutica, "um dia por mil anos", embora não fique claro qual a fonte dessa ideia (talvez de Sl 90:4, como fazem alguns intérpretes contemporâneos).

Avançando no tempo, nota-se que Fílon de Alexandria (morte em c. 42 d.C.), intérprete judeu, passou a utilizar o método alegórico originado na literatura helenística (WALKER, 2015, p. 28). Ele aplicou esse método ao Antigo Testamento e isso influenciou seu entendimento acerca do relato da criação (SHEA, 2011, p. 496; ver também LEWIS, 1989, p. 434) e sua influência foi sentida sobre a geração de intérpretes cristãos treinados em Alexandria no século seguinte.

O autor da epístola de Barnabé aplicou o método alegórico na interpretação dos dias da criação:

Escutem, meus filhos, o significado dessa expressão, "Ele terminou em seis dias". Isso implica que o Senhor acabará com todas as coisas em seis mil anos, pois um dia para ele significa mil anos. Ele próprio testifica, dizendo: "Eis que um dia será como mil anos." Portanto, meus filhos, em seis dias, ou seja, seis mil anos, todas as coisas acabarão (Epístola de Barnabé, 15).

Mais uma vez é perceptível a influência da ideia de equivaler um dia a mil anos. Embora o autor dessa epístola não esteja diretamente comentando os dias da criação, ele encontra um significado simbólico e o aplica escatologicamente. Lewis (1989, p. 436-444) sugere que intérpretes posteriores, como os alexandrinos Clemente (morte c. 215) e Orígenes (182/185-251/254), e 
também Agostinho (354-430), conhecidos por empregar o método alegórico, entendiam, ainda que em certa medida, de forma não literal os dias da criação.

Nas palavras de Agostinho, o sentido dos dias da criação seria algo "extremamente difícil, talvez impossível para nós compreendermos, quanto mais dizê-lo" (Agostinho, City of God, 11.7, tradução livre). Ainda assim, tentou encontrar algum significado simbólico, não evidente no texto, para os dias da criação. Sobre isso, ele escreveu:

Essas obras [da criação] estão registradas como tendo sido completadas em seis dias (o mesmo dia sendo seis vezes repetido), porque seis é um número perfeito, não porque Deus precisasse de um tempo prolongado, como se Ele não pudesse criar todas as coisas de uma vez, o que então deveria marcar o curso do tempo pelos próprios movimentos, mas porque a perfeição da obra é significada pelo número seis (City of God, 11.30, tradução livre) $)^{3}$.

Lavallee (1989, p. 459-460) opina que Agostinho tentou resolver dificuldades exegéticas, dentre elas a harmonização entre os seis dias de Gênesis 1, o dia que aparece em Gênesis 2:4 ("estas são as origens dos céus e da terra, quando foram criados; no dia em que o SENHOR Deus fez os céus e a terra" - ARC, grifo nosso) e o apócrifo Sirach 18:1 ("Aquele que vive para sempre criou todas as coisas juntas" - grifo acrescido, tradução livre), partindo do pressuposto de que esses textos aparentemente colocam a criação como simultânea ${ }^{4}$. Outra dificuldade seria a contagem do tempo antes da existência de sol e lua, criados no quarto dia (LAVALLE, 1989, p. 462-463; ver City of God, 11.7).

Durante a Idade Média, o debate continuou (LEWIS, p. 450-452). Parte dessa discussão adveio da influência de Agostinho quanto ao suposto ponto de controvérsia já mencionado. A descontinuidade veio com a Reforma, quando houve em certa medida o retorno à interpretação literal dos dias da criação (LEWIS, 1989 p. 451, 452-453). Contudo, essa percepção veio a ser novamente desafiada a partir dos séculos 18 e 19, com o advento do racionalismo e do iluminismo, num contexto fortemente influenciado pelo progresso das ciências naturais. Segundo Shea (2011, p. 498-499):

Esses progressos filosóficos causaram impacto sobre o relato bíblico da criação de duas formas diferentes, mas paralelas. A primeira diz respeito à crítica literária do relato bíblico; e a segunda tem que ver com a afirmação de que a ciência teria demonstrado a inexatidão do relato bíblico da criação. Esses dois métodos de avaliação do registro bíblico subsistem até hoje.

O primeiro novo método originou-se com Jean Astruc (1684-1766), médico francês, que acreditava que Gênesis fora uma compilação de fontes antigas (SHEA, 2011, p. 499; WALKER, 2015, p. 733). Essa perspectiva foi desenvolvida com o tempo até cristalizar-se na chamada "hipótese documental", proposta por Julius Welhausen (1844-1918). Uma vez que o Gênesis passou a

\footnotetext{
3 É curioso que Agostinho "prove" seu argumento através de um raciocínio matemático, envolvendo o número seis. Já em seu argumento para a perfeição do número sete, ele se vale de ambos raciocínios matemático e bíblico (ver City of God, 11.30-31).

4 Lavallee (1989, p. 460) critica o fato de essa dificuldade de Agostinho com o texto ter se originado pelo seu uso de uma tradução latina da Septuaginta (que em si já é uma tradução do original hebraico e aramaico) e também de sua dependência de uma tradução latina (imprecisa, por sinal) de material apócrifo.
} 
ser considerado uma edição de fontes, por sua vez realizada em tempos posteriores ao de Moisés, alegou-se que não poderia, portanto, constituir-se em história confiável (SHEA, 2011, p. 499).

O segundo novo método foi se fortalecendo a partir do século 18, à medida que a geologia e a biologia modernas foram sendo desenvolvidas. A percepção do tempo geológico como compreendendo milhões de anos, a partir de interpretações do registro fóssil, bem como a hipótese evolutiva proposta por Darwin (SHEA, 2011, p. 500-501) foram um golpe na visão literal do relato da criação.

Isso provocou uma reação dos intérpretes e estudiosos da Bíblia, que para torná-la compatível com as novas descobertas, optaram por resgatar alguns dos antigos argumentos para a interpretação não literal de Gênesis 1 e 2. Um deles é a ideia de que um dia equivale a mil anos (a partir da aplicação arbitrária dos textos de Sl 90:4 e 2 Pd 3:8); outro, a chamada teoria do "dia-revelação" ou "dia-pictórico", segundo a qual os seis dias de Gênesis 1 não eram a duração cronológica da criação, mas do período em que o escritor do Gênesis recebeu a revelação que deu origem ao relato (LEWIS, 1989, p. 454-455).

Como implicação desse cenário, observou-se nos Estados Unidos, no final do século 19 e começo do século 20, que os intérpretes cristãos se dividiram entre os que defendiam a literalidade do Gênesis, entre outras questões teológicas (conhecidos como conservadores), e aqueles que procuraram "reter a orientação evangélica, mas refazendo sua fé de modo a ficar em sintonia com o pensamento científico e histórico da época" (WALKER, 2015, p. 778), conhecidos como "liberais".

Esse é, de forma bastante sintética, o panorama histórico da discussão sobre a literalidade dos dias da criação. Nota-se na atualidade a emergência e reconfiguração da percepção da não literalidade. Enquanto que da antiguidade até a Idade Média a visão dos dias da criação como períodos de tempo indefinidos ou mais longos baseou-se em fatores filosóficos, ou foi proposta como solução para dificuldades exegéticas, a partir da Idade Moderna até os dias de hoje, ela ressurgiu como reação aos questionamentos feitos por cientistas ao relato criativo do Gênesis, com o fim de ajustá-lo às descobertas das ciências naturais que, à primeira vista, contradiziam a visão bíblica.

É apropriado, a esta altura, revisitar o relato bíblico acerca da criação para buscar as reivindicações do próprio texto.

\section{O uso de yôm em Gn 1:1-2:3}

Para um estudo resumido do significado de "yôm" (dia) no contexto da narrativa da criação, é importante notar a perícope que compreende todo o primeiro capítulo de Gênesis e os três primeiros versos do segundo.Essa porção é tida como uma unidade literária, muito embora seu conteúdo na maioria das Bíblias apareça dividido de forma arbitrária (YOUNKER, 2010, p. 119). "Yôm” aparece nessa perícope 14 vezes (uma delas no plural "yāmîm” (dias) em Gn 1:14. Sobre o seu uso, Kaiser Jr. (1980, p. 77) lembra que

até essa altura, o leitor fica conhecendo a elasticidade do autor no seu emprego da palavra "dia": tem o mesmo alcance de significados diferentes que se conhece no português moderno. É igual à luz do dia (1:5); nossos dias civis que formam o ano (v. 14); e a extensão total da criação, ou, como diríamos, o dia da onça (grifo do autor). 
Essa palavra, então, apresenta um campo semântico amplo e esse fator, segundo Steinmann (2002, p. 584), "por si só tornou a duração dos dias de Gênesis 1 um assunto perenemente controverso". Por isso, a correta interpretação do termo deve levar em consideração o contexto (MOSKALA, 2010, p. 116), e, ao contrário do que afirma Schultz (2009, p. 27, nota no 5), a narrativa da criação pode fornecer elementos determinantes para o significado dos "dias" relatados. Isso será destacado, ainda que de forma breve, nas próximas linhas.

\section{Tipo de literatura da perícope}

É importante perceber qual o gênero literário da perícope de Gênesis 1:1-2:3, já que, "há tempo é reconhecido que o gênero desempenha um importante papel na interpretação" (OSBORNE, 2005 p. 679, tradução livre). No verso que segue à conclusão da perícope, Gênesis 2:4, lê-se que o relato criativo conta as "tôledoț", "a história das origens" (Nova Versão Internacional). Sabendo que o livro de Gênesis é dividido em dez genealogias, ou "tôledoț" (Gn 2:4; 5:1; 6:9; $10: 1 ; 11: 10 ; 11: 27 ; 25: 12 ; 25: 19 ; 36: 1 ; 37: 2)$, Moskala (2010, p. 116, tradução livre) afirma que se elas "são literais, e esses personagens [Adão, Noé, Abraão, Isaque, Jacó e José] são históricos, isso sugere que a genealogia dos céus e da terra deve ser interpretada da mesma maneira. Deve-se ser consistente; ou todas as genealogias são literais ou nenhuma o é".

Assim, o contexto amplo da perícope aponta para um relato literal, sem simbolismos. Sobre ele, ainda é possível distinguir dois contextos específicos do uso de "yôm": $1^{\circ}$ ) uso com numeral ordinal ( 9 ocorrências) e $2^{\circ}$ ) uso em relação a termos astronômicos (5 ocorrências).

\section{Uso com numeral ordinal}

Vê-se que "yôm" é acompanhado de um numeral ordinal ao final dos trechos que descrevem diferentes etapas da criação divina ( $\mathrm{Gn} 1: 5,8,13,19,23,31 ; 2: 2-3)^{5}$. Construções semelhantes, descrevendo uma sucessão de períodos de 24 horas, são relatadas em Números 7:12-88 e 29:1-38, (consagração do altar do santuário de Moisés e das cerimônias da festa dos tabernáculos, respectivamente). Moskala (2010, p. 116) afirma que "quando a Bíblia, em um relato histórico, usa a palavra 'dia' em combinação com um numeral, consistentemente se refere a um dia regular". Shea (2011, p. 470) expande esse argumento para incluir a expressão paralela "tarde e manhã":

\footnotetext{
Cada afirmação [ao final do relato de cada etapa da criação] contém quatro elementos. Primeiro é o verbo "haver", que, na verdade, aparece duas vezes. Segue-se a menção das partes escura e clara do dia: a tarde e a manhã. Em terceiro lugar, numera-se o dia. Em quarto e último lugar, aparece a palavra "dia" propriamente dita. Afirma-se nessa complexa fórmula cronológica que os elementos temporais surgiram, que se reuniram para formar o dia e que cada dia foi numerado. Quando se faz o confronto entre esse tipo de fórmula cronológica e outras evidências do AT (ver Gn 33:13; Êx 12:18 e Ne 5:18), não fica nenhuma dúvida de que o escritor estava falando de um período de luz e trevas de 24 horas, que compunha um dia inteiro. A adição dos outros elementos dessa fórmula à palavra "dia" dá uma especificidade que exige a aplicação limitada e local dessa locução no tempo (SHEA, 2011, p. 470, grifos nossos).
}

5 Embora o numeral cardinal "echad" acompanhe "yôm” em 1:5, Steinmann discute a construção singular desse verso em seu artigo. 
Nota-se essa mesma relação entre a expressão "tarde e manhã" e um "dia" em outra parte da Bíblia Hebraica, a saber, Daniel 8:14 (NICHOL, 2011, p. 191): "até duas mil e trezentas tardes e manhãs". Schwantes (2009, p. 390) chega a afirmar que "o autor do livro de Daniel tomou emprestada a frase 'tarde manhã' de Gênesis 1". Uma vez que, nesse livro, são comuns períodos de tempo descritos na forma de "tempos", "semanas" e "dias", é possível assim enxergar de forma mais clara o paralelo entre a expressão "tarde e manhã" e o período de 24 horas chamado "dia". 6

Steinmann (2002, p. 584), argumentando em um sentido diferente, chega à mesma conclusão. Para ele, as construções gramaticais que descrevem os dias da criação são singulares, e não refletem o uso comum de numerais com a palavra "yôm" no resto da Bíblia Hebraica (Steinmann, 2002, p. 582). Sua opinião é que em Gênesis 1:5 ocorre um uso incomum de "'echad"(um) com a palavra "yôm" numa expressão indefinida (sem a presença de artigo, contrariando o uso comum dessa expressão em outros contextos da Bíblia Hebraica). Por isso, relaciona essa construção singular com o que se relata em Gênesis 1:3-5, a saber, à criação da luz e à delimitação das partes clara e escura do dia, em termos de "dia" e "noite", na sucessão de "tarde" e "manhã".

A conclusão é que, em vez de ser entendido como sinônimo de numeral ordinal e ser traduzido como "primeiro [dia]", "echad" tem a função no texto de numeral cardinal, e assim qualifica a primeira etapa da criação como "um dia" convencional, uma sucessão de claro e escuro, tarde e manhã (STEINMANN, 2002, p. 583-584). Os demais numerais, até o quinto dia, embora sejam ordinais, refletiriam essa definição de dias solares, de 24 horas (STEINMANN, 2002, p. 583), enquanto que o sexto e o sétimo dia, por apresentarem artigo definido junto ao numeral, seriam assim dias especiais, dados os eventos que neles ocorreram (STEINMANN, 2002, p. 583).

Os argumentos de Steinmann seguem um rumo distinto do que muitas traduções e comentaristas tomam ${ }^{7}$. A inclusão deles aqui fornecem uma ponte entre o uso de "yôm" com numeral, como apresentado até aqui, e o uso da palavra em contextos astronômicos, que é apresentado a seguir.

\section{Uso de "yôm" em contextos astronômicos}

Quando considerado o uso de "yôm" em contextos astronômicos, a percepção de seu significado literal como período de 24 horas fica ainda mais evidente. De forma especial, tal uso compreende a primeira e a quarta etapa da criação (Gn 1:3-5, 14-19). Nelas, são criados, respectivamente, a separação entre a luz (que Deus denomina "dia") e a escuridão (que ele chama "tarde"); e os "luzeiros no firmamento", que são destinados a "separar" e "governar" o "dia/manhã" e a "noite/tarde", através da atividade de "alumiar" a terra.

Uma vez que os luzeiros devem "alumiar" a terra, é um desenvolvimento lógico o que a narrativa descreve (Gn 1:16): “o maior" governaria o dia (o sol determina o período claro) e “o menor" a noite (a lua "iluminando" o período escuro). Essa sucessão de período claro e escuro,

\footnotetext{
6 É verdade que esse verso de Daniel está inserido em um tipo diferente de literatura, a saber, a apocalíptica, e, "considerando o contexto, essas predições de tempo não podem ser entendidas literalmente" (JOHNSON, 2011, p. 882). Assim, o termo "dia", nas profecias de Daniel, equivalem simbolicamente a ano, como atestado em profecias contidas em outros tipos de literatura da Bíblia Hebraica, como a narrativa histórica (Nm 14:34), e a profética clássica (Ez 4:5 e 7). Nesses casos, no entanto, é notável que cada dia referencial correspondente ao período de um ano é um dia literal, de 24 horas. Nesse contexto, é válido enfatizar, mais uma vez, os paralelos entre os termos temporais que aparecem nos capítulos proféticos de Daniel (capítulos 7-12; sobre a unidade entre esses capítulos, ver Shea (2009, p. 183-185).

7 Steinmann menciona esse fato na introdução de seu artigo (STEINMANN, 2002, p. 577). De fato, algumas traduções da Bíblia em português também seguem a ideia de que o numeral cardinal "'echad", em Gn 1:5, seria usado como ordinal, como a Almeida Revista e Atualizada, a Nova Versão Internacional e a Nova Tradução na Linguagem de Hoje.
} 
sol e lua, reflete a relação literária que existiria entre a primeira e a quarta etapa da criação (SHEA, 2011, p. 472), e, assim, que os dias da criação "não devem ser considerados como períodos de tempo de incalculável duração, de anos ou milhares de anos, mas como simples dias terrestres" (KEIL; DELITZSCH, 1864, p. 51, tradução livre).

Os luzeiros também eram destinados, segundo o relato, a serem para "sinais, para estações, para dias e anos" (Gn 1:14, grifo nosso). De forma reconhecível, sol e lua aparecem como os agentes naturais da sucessão de períodos astronômicos (SHEA, 2011, p. 472). Um deles, segundo o texto, é o período chamado "dia" (yôm), de 24 horas (que aparece como o plural "dias").

\section{Textos relacionados}

É pertinente, nesse ponto, mencionar o uso especial de "yôm” em Gênesis 2:4. Esse verso, que liga Gênesis 1 ao capítulo seguinte, diz: "estas são as origens dos céus e da terra, quando foram criados; no dia em que o SENHOR Deus fez os céus e a terra" (Almeida Revista e Corrigida, grifo nosso). Como já antes mencionado, esse verso originou discussões entre os intérpretes cristãos ao longo da história. Se tomada literalmente, essa ocorrência da palavra aparenta contradizer a cronologia do capítulo anterior, da criação em seis dias.

Como já mencionado, a palavra "yôm" possui um campo de significados amplo, tal qual ocorre na língua portuguesa. Por isso, o contexto acaba por ser essencial para seu correto entendimento. Já foi mostrado que, em Gênesis 1:1-2:3, essa palavra está relacionada ao período de 24 horas que chamamos "dia" (ainda que nos contextos do primeiro e quarto dia ela signifique a parte clara das 24 horas). Como, então, entender o que ela significa em Gênesis 2:4?

Em primeiro lugar, a percepção de que Gênesis 1 e 2 são capítulos em paralelo (SHEA, 2011, p. 479; ver também NICHOL, 2011, p. 204) é uma salvaguarda contra qualquer interpretação que os coloque como paradoxais. Assim, Gênesis 2:4 não pode contradizer o que é contado no capítulo anterior.

A ciência do campo semântico de "yôm" pode ajudar a elucidar a questão. Em Gênesis 2:4 o termo pode muito bem ser tomado como expressão temporal genérica, englobando assim todos os dias de 24 horas da criação, da maneira como várias traduções modernas a compreenderam: "esta é a gênese dos céus e da terra quando foram criados; quando o SENHOR Deus os criou" (Almeida Revista e Atualizada, grifo acrescido); "Esta é a história das origens dos céus e da terra, no tempo em que foram criados: Quando o Senhor Deus fez a terra e os céus" (Nova Versão Internacional, grifo acrescido).

Êxodo 20:11, embora não se encontre na perícope de Gênesis 1:1-2:4, faz uma referência direta a ela. No verso, que conclui o quarto mandamento do decálogo, lê-se: "porque em seis dias fez o SENHOR os céus e a terra, o mar e tudo o que neles há e, ao sétimo dia, descansou; por isso, o SENHOR abençoou o dia de sábado e o santificou”. Esse texto é relevante para o estudo do significado de "yôm" na narrativa da criação porque liga as sete etapas criativas aos sete dias da semana literal.

Na verdade, cada dia literal da criação é o fundamento para a contagem de tempo em uma semana de sete dias de 24 horas. E o sétimo dia da criação, no qual Deus descansou de sua obra, é a base para a instituição do mandamento do descanso no sétimo dia da semana. Se os dias da criação não correspondessem a dias comuns de 24 horas, não haveria coerência para o mandamento. 
Em resumo, a observação da perícope de Gênesis 1:1-2:3 evidencia que a maneira correta de se interpretar a palavra "yôm" na narrativa da criação é como um período literal de 24 horas. Soma-se, para essa conclusão, evidências como: o tipo de literatura representada pela história de Gênesis 1 e 2; evidências sobre seu uso em outras partes da Bíblia Hebraica, em especial com numerais; o paralelo com a expressão "tarde e manhã" e a relação com a sucessão astronômica entre período claro/escuro do dia, sol/lua, evidente nos trechos do primeiro e do quarto dia da criação.

Uma vez que o texto apresenta tais reivindicações interpretativas, nota-se que os fatores metodológicos estão necessariamente envolvidos na discussão sobre o significado dos dias da criação. Ou tais fatores serão os reivindicados pelo próprio texto, ou serão outros estranhos a ele.

\section{Considerações metodológicas}

É possível entender a influência de fatores metodológicos na discussão sobre o significado de "yôm" em Gênesis 1:1-2:3, tanto em termos de exegese quanto em termos dos pressupostos hermenêuticos. Na verdade, ambos estão intimamente relacionados, são interdependentes, e, partindo desse ponto de vista, serão abordados nas linhas seguintes de forma conjunta.

Como Hasel (1994) aponta, duas passagens bíblicas têm sido comumente usadas como uma espécie de chave hermenêutica por proponentes de um significado não literal, de longo período de tempo, para os dias da criação: Salmo 90:4 ("pois mil anos aos teus olhos são como o dia de ontem que se foi e como a vigília da noite") e 2 Pedro 3:8 ("para o Senhor, um dia é como mil anos, e mil anos, como um dia").

Ele enumera, também, uma série de razões porque essas passagens não podem ser usadas para a exegese de Gn 1 e 2, entre elas: (1) o fato de ambas não estarem inseridas num contexto de referência à criação; e (2) apresentarem partículas comparativas relacionadas à palavra "dia": no Salmo 90:4, "ke" (como), e em 2 Pedro 3:8, "hôs", (como), o que não ocorre em Gênesis (HASEL, 1994). Assim, essa evidência indica que essas duas passagens não servem como base para a exegese dos dias da criação.

Outro fator determinante para a interpretação dos dois primeiros capítulos de Gênesis é o caráter histórico ou não atribuído a ela pelo intérprete. Hasel (1994) mais uma vez lança luz sobre a questão ao lembrar como vários autores abrem margem para uma interpretação não literal dos dias da criação e dos outros elementos da narrativa ao rotularem-na como "lenda", "saga", "poema", entre outros. Essa leitura não literal é assim comentada por Roitman (2015, p. 55):

\footnotetext{
Alguns podem estar se perguntando: que importância tem estabelecer a distinção entre "história" e "literatura"? No entanto, essa distinção é fundamental. Na época em que o fundamentalismo e o literalismo têm se alastrado com força incomum entre os devotos das três religiões monoteístas, torna-se, portanto, essencial distinguir as duas categorias de análise ao estudar a Bíblia ou qualquer outra fonte escrita, e assim evitar cair na apologia selvagem, no cientificismo barato ou nos erros crassos.
}

Esses rótulos, entretanto, vão de encontro ao que é assumido pelo autor de Gênesis, que reivindica em seu texto um relato literal e histórico da criação. É notável que outros personagens históricos da Bíblia, como Jesus Cristo e os apóstolos no Novo Testamento, também tomavam a narrativa do livro de Gênesis da mesma maneira. Como lembra Davidson (2011, p. 81), "de fato, 
todo escritor do NT confirma, explícita ou implicitamente, a historicidade de Gênesis 1-11 (ver Mt 19:4-5; 24:37-39; Mc 10:6; Lc 3:38; 17:26-27; Rm 5:12; I Co 6:16; 2 Co 11:13; Ef 5:31; 1 Tm 2:13-14; Hb 11:7; 1 Pd 3:20; 2 Pd 2:5; Tg 3:9; 1 Jo 3:12; Jd 11, 14; Ap 14:7)" (grifo do autor) ${ }^{8}$.

Esse reconhecimento da literalidade dos primeiros capítulos de Gênesis, por parte dos autores neotestamentários, levou Payne (1965, p. 85) a concluir que:

Tais métodos de interpretação [que tomam Gênesis 1 e 2 como não literais][...], sejam eles designados como 'míticos', 'parabólicos', ou 'figurativos', permanecem como que condenando a si próprios, à luz de ambos: o próprio formato literário conhecido de Gênesis e da analogia do resto da Escritura, que assume ao longo de si mesma a sua historicidade literal [do relato de Gênesis 1 e 2]" (tradução livre).

Van Groningen (1970) vai mais longe e estabelece a hermenêutica neotestamentária acerca de Gênesis como um modelo a ser seguido:

O Novo Testamento não apenas fornece a necessária orientação material, ele também dá uma orientação básica para o método de interpretação. Os escritores inspirados do Novo Testamento nos dão dicas, sugestões, indicações, e às vezes exemplos completos acerca de como interpretar Gênesis. E certamente é verdade que se os escritores do Novo Testamento são apropriadamente considerados inspirados, como de fato são, o fato de considerarem Gênesis como revelação de fatos e eventos históricos deve ser aceita e seguida (VAN GRONINGEN, 1970, p. 215, tradução livre).

Fica evidente que essa discussão hermenêutica aponta para percepções mais profundas, para pressupostos que guiam o intérprete em sua atividade interpretativa (VAN GRONINGEN, 1970, p. 205). Argumentando em nível macro hermenêutico, Canale (2014, p. 108) identifica a presença e influência desses pressupostos na interpretação ao lembrar que:

Alguns presumem que a teologia bíblica é compatível com a história do tempo profundo/evolução. Para eles, a fim de harmonizar a evolução com a teologia bíblica basta interpretar Gênesis 1 teologicamente, isto é, de maneira não literal. Se fizéssemos uma pequena concessão como essa [pensam eles], a teologia e as doutrinas bíblicas não só permaneceriam inalteradas, mas também se tornariam relevantes para aqueles que estão convencidos da veracidade do tempo profundo e das ideias evolutivas. A credibilidade intelectual da igreja cresceria e seu apelo intelectual seria ampliado.

Dessa forma, nota-se que as questões exegéticas estão subordinadas a pressuposições quanto à natureza do relato bíblico, se é literal ou alegórico, e à veracidade de seu conteúdo. Tais pressupostos impactam diretamente a interpretação, ainda que inconscientemente. O conteúdo da revelação é julgado à luz de paradigmas científicos, tais como a hipótese evolutiva da biologia e o uniformismo da geologia.

$\mathrm{Na}$ teologia, essa prática fica mais evidente através do emprego do chamado "método histórico-crítico", que analisa o que as narrativas bíblicas contam através de "analogias com outras experiências históricas", sem espaço para a "transcendência" (HASEL, 2015, p. 200). A partir desta

\footnotetext{
8 Ver também TIMM (2015).
} 
metodologia, relatos que não apresentam paralelos históricos posteriores e, assim, contradigam as hipóteses científicas amplamente aceitas (como o aparecimento da vida no planeta e as transformações cósmicas e geológicas nele ocorridas, descritos em Gênesis 1 e 2 como resultantes de ação sobrenatural em tempo curtíssimo), são logo interpretadas como alegorias. Nas palavras de Hasel (2015, p. 201), "se nossa concepção de história não nos permite reconhecer uma intervenção divina na história através de atos e palavras, então não temos condições de lidar de maneira adequada e apropriada com o testemunho da Escritura”.

De fato, como observado, o estudo do texto bíblico revela uma realidade diferente daquelas defendidas pelas reconstruções histórico-críticas. A Bíblia reclama a literalidade e a historicidade de seu relato, e, assim, da existência e atuação sobrenatural de Deus. Nesse ponto, a pergunta de Canale, colocada no início, pode ser respondida: "Os seis dias de 24 horas apresentados em Gênesis 1 são um componente essencial da verdade teológica bíblica”?

O texto reivindica um "sim" como resposta. Os dados bíblicos o exigem. A própria coerência interna da Bíblia depende disso (CANALE, 2014, p. 109) ${ }^{9}$. Nas palavras de Van Groningen (1970, p. 218, tradução livre), "o entendimento adequado do início é crucialmente importante para a Bíblia inteira”. Não é mera questão de diferentes conclusões interpretativas. Enxergar os dias da criação como períodos indefinidos ou longos extrapola os termos interpretativos estabelecidos pelo próprio texto interpretado. Reflete a adoção de pressupostos extrabíblicos, sejam eles filosóficos ou científicos.

Nesse contexto, é legítima a preocupação de Canale (2014, p. 115) ao mencionar que "a teologia cristã não pode harmonizar a criação bíblica à história do tempo profundo/evolução sem alterar sua essência, doutrinas e sistema teológico". Van Groningen (1970, p. 218, tradução livre) ilustra isso ao enumerar que "a maravilha da Redenção, a glória do nosso Senhor, o pleno dever do ser humano, é tornado mais claro para nós por meio da interpretação de Gênesis, que estabelece grandes fatos históricos na forma de eventos históricos".

\section{Considerações finais}

Como visto, a narrativa da criação, em especial a descrição de suas etapas em termos de "dias", foi e ainda é fonte de grande debate. Historicamente, questões filosóficas e em seguida científicas influenciaram o entendimento de intérpretes e teólogos sobre como deveriam compreender temporalmente os dias relatados em Gênesis 1:1 a 2:3. A interpretação do texto, quando feita levando-se em consideração não apenas o campo semântico da palavra em si, mas também o contexto em que aparece e aquele mais amplo fornecido pela Escritura, revela que a forma correta de entendimento sobre o termo "dia", quando descreve cada uma das etapas criativas, é de um período literal de 24 horas.

Fica evidente, entretanto, que questões mais amplas relacionadas à metodologia hermenêutica e teológica precisam ser reconsideradas. A macro-hermenêutica precisa ser levada em conta para que a Bíblia "fale por si mesma" e a interpretação do texto não se torne uma "eisegese", ditada por pressupostos extrabíblicos, sejam eles filosóficos ou de caráter científico/naturalista.

9 Ver também o artigo de Norman Gulley (2004), "What happens to Biblical truth if SDA church accepts theistic evolution?". 
Em suma, a relação texto-método-interpretação é clara. $\mathrm{O}$ método faz a mediação entre o texto e sua interpretação. Quando o intérprete observa o método reivindicado pelo próprio texto, tal roteiro serve de elemento de conformação da interpretação. Quando, porém, desprestigia parcial ou totalmente - o método ali reivindicado, inevitavelmente produzirá uma interpretação desconforme ao próprio texto. Nesse caso, ainda que apresente perspectivas criativas e interessantes sobre o texto, não fará jus às suas reivindicações e características intrínsecas. O que ocorre na interpretação da narrativa da criação serve de alerta quanto a isso.

\section{Referências}

Agostinho de Hipona. City of God. In: DODS, M. (ed.). The Works of Augustine, Bishop of Hippo: a new translation. Translated by Marcus Dods, George Wilson and J. J. Smith. Edinburgh: T. and T. Clark, 1913.

CANALE, F. Criação, Evolução e Teologia: uma introdução aos métodos científicos e teológicos. Tradução de Matheus Cardoso. Engenheiro Coelho, SP: UNASPRESS, 2014.

CHARLES, R. H. (ed.). The Book of Jubilles or the Little Genesis: translated from the editor's Ethiopic text and edited, with introduction, notes and indices. London: Adam and Charles Black, 1902. Disponível em: <http://bit.ly/3buH8mR>. Acesso em 19 mai 2018.

DAVIDSON, R. M. Interpretação Bíblica. In: DEDEREN, R. (ed.). Tratado de Teologia Adventista do Sétimo Dia. Tradução de José Barbosa da Silva. Tatuí, SP: Casa Publicadora Brasileira, 2011.

Epístola de Barnabé. Disponível em: <http://bit.ly/2HhIljx>. Acesso em 119 mai 2018.

GULLEY, N. G. What happens to Biblical truth if SDA church accepts theistic evolution? Journal of the Adventist Theological Society, v. 15, n. 2, p. 40-58, 2004.

HASEL, G. F. The "Days" of Creation in Genesis 1: Literal "Days" or Figurative "Epochs/Periods" of Time?. Geoscience Research Institute, 1994. Disponível em: <http://bit.ly/2SN8FbS >. Acesso em 16 mai 2018.

HASEL, G. F. Teologia do Antigo e Novo Testamento: questões básicas no debate atual. Tradução de Luís M. Sander e Jussara Marindir P. S. Arias. São Paulo: Academia Cristã, 2015.

JOHNSON, W. G. Apocalíptica Bíblica. In: DEDEREN, R. (ed.). Tratado de Teologia: Adventista do Sétimo Dia. Tradução de José Barbosa da Silva. Tatuí, SP: Casa Publicadora Brasileira, 2011.

KAISER JR. W. C. Teologia do Antigo Testamento. Tradução de Gordon Chown. São Paulo: Vida Nova, 1980.

KEIL, C. F.; DELITZSCH, F. Commentary on the Old Testament: The Pentateuch. Translated from German by Rev. James Martin. Edinburgh: T. and T. Clark, 1864. v. 1.

LAVALLEE, L. Augustine on Creation Days. Journal of the Evangelical Theological Society. v. 32, n. 4, p. 457-464, 1989. Disponível em: <http://bit.ly/2SHkten>. Acesso em 05 jun $2018 .$.

LEWIS, J. P. The Days of Creation: an historical survey of interpretation. Journal of the Evangelical Theological Society. v. 32, n. 4, p. 433-455, 1989. Disponível em: <http://bit.ly/2OSGIwL >. Acesso em 17 mai 2018. 
MOSKALA, J. Were the Creation days 24-hour days or indefinite periods of time? Genesis 1:5. In: PDFANDL, G. (ed.). Interpreting Scripture: Bible questions and answers. Silver Spring: Biblical Research Institute, 2010.

NICHOL, F. D. (ed.). Comentário Bíblico Adventista do Sétimo Dia: Gênesis a Deuteronômio. Vários tradutores. Tatuí, SP: Casa Publicadora Brasileira, 2011. v. 1.

OSBORNE, G. R. Historical narrative and truth in the Bible. Journal of the Evangelical Theological Society, v. 48, n. 4, p. 673-698, 2005. Disponível em: <http://bit.ly/2SIoTBF>. Acesso em: 05 fev 2019.

PAYNE, J. B. Theistic Evolution and the Hebrew of Genesis 1-2. Bulletin of the Evangelical Theological Society. v. 8, n. 2, p. 85-90, 1965. Disponível em: $<$ http://bit.ly/31Sw4LQ >. Acesso em 29 mai 2018.

ROITMAN, A. D. Bíblia, Exegese e Religião: uma leitura do judaísmo. Tradução de Reginaldo Souza. São Paulo: Editora Vida, 2015.

SCHULTZ, S. J. A História de Israel no Antigo Testamento. Tradução de João Marques Bentes. São Paulo: Vida Nova, 2009.

SCHWANTES, S. J. 'Ereb Boqer de Daniel 8:14 reexaminado. In: HOLBROOK, F. B. Estudos sobre Daniel: origem, unidade e relevância profética. Tradução de Francisco Alves de Pontes e Fernanda Caroline de Andrade Souza. Engenheiro Coelho, SP: UNASPRESS, 2009.

SHEA, W. H. Criação. In: DEDEREN, R. (ed.). Tratado de Teologia Adventista do Sétimo Dia. Tradução de José Barbosa da Silva. Tatuí, SP: Casa Publicadora Brasileira, 2011.

SHEA, W. H. A Unidade de Daniel. In: HOLBROOK, F. B. Estudos sobre Daniel: origem, unidade e relevância profética. Tradução de Francisco Alves Pontes e Fernanda Caroline de Andrade Souza. Engenheiro Coelho, SP: UNASPRESS, 2009.

SIRACH. Translated by Box and Oesterley. In: CHARLES, R. H. (ed.). The Apocrypha and Pseudepigrapha of the Old Testament In English: with introduction and critical and explanatory notes to the several books. Oxford: Clarendon Press, 1913. v. 1.

STEINMANN, A. E. 7 T as an ordinal number and the meaning of Genesis 1:5. Journal of the Evangelical Theological Society. v. 45, n. 4, p. 577-584, 2002. Disponível em: <http://bit.ly/39qSBlo $>$. Acesso em 01 fev 2019.

TIMM, A. R. O Sábado na Bíblia: Por que Deus faz questão de um dia. Tatuí, SP: Casa Publicadora Brasileira, 2015.

VAN GRONINGEN, G. Interpretation of Genesis. Journal of the Evangelical Theological Society. v. 13, n. 4, p. 199-218, 1970. Disponível em: <http://bit.ly/2SF3Dgh>. Acesso em 02 jun 2018.

WALKER, W.; NORRIS, R. A.; LOTZ, D. W.; HANDY, R. T. História da Igreja Cristã. Tradução de Paulo D. Siepierski. São Paulo: ASTE, 2015.

YOUNKER, R. W. Are there two contradictory accounts of Creation in Genesis 1 and 2? Genesis 2:4-6. In: PFANDL, G. (ed.). Interpreting Scripture: Bible questions and answers. Silver Spring: Biblical Research Institute, 2010. 